\title{
The enemy of the good
}

\section{How specifics in publisher's green OA policies are bogging down IR deposits of scholarly literature}

n the evolving landscape of scholarly

communication, librarians not only spend countless hours educating researchers about copyright, subscription licensing, classroom use, author's agreements, and open access, but they also pay enormous subscription fees to publishers. This is potentially the reality of a system in flux, the fact of being in the middle of a change: we work for reform and enforce the current system in the same breath. Librarians tend to be risk averse, and rightly so, but this caution should not mean that librarians are pacifiers instead of change agents, that we educate while accepting publisher's models without question or action.

Green open access, the subsection of open access in which no additional money changes hands and a version of a paper is posted online, is the most financially available means of providing broad access to research for many authors and consumes a great amount of librarian time. The most common format of green open access is the deposit of postprints, versions of papers that have been through peer-review but often not copyediting or journal layout and typesetting. Journal publishers allow these versions to be posted with restrictions, based on an understanding that scholars will seek the version of record and cite that work in any future publication. Therefore, the secondary versions do not impede the most valuable metric of journal publication-citations-and do not impact subscriptions, as discovery happens at an individual level and purchasing at an institutional level

The Berne Convention for the Protection of Literary and Artistic Works expresses that copyright should "protect in as effective and uniform a manner as possible the rights of authors over their literary and artistic works." The current system of green open access lacks effective or uniform processes and stipulations, thus delaying and inhibiting the rights that publishers claim they give back to authors of academic journal articles. As a result, authors are turning to alternate sources to share and access journal articles. These social media or file sharing sources operate outside of copyright.

\section{The Internet has changed access to research}

The Internet is a powerful medium for knowledge dissemination that has greatly increased access to published knowledge. Institutional repositories have proliferated to embrace and expand this digital landscape,

Leila Sterman is scholarly communication librarian at Montana State University, email: leila.sterman@ montana.edu

(c) 2017 Leila Sterman 
yet depositing the precise copy of an article allowed by journal publishers is made needlessly cumbersome by restrictions that are neither clear nor consistent. In this way, publishers punish the people attempting to follow their guidelines by increasing the time and effort for each repository deposit.

These restrictions are in place to protect the business model and profit margins of publishers, yet when they feel stress from outside forces, most recently by Sci-Hub and similar file sharing sources, publishers seem to attack libraries - their largest paying customers, instead of fixing the problems themselves. Suggestions that by tightening library access (two-step authentications, etc.), publishers can fix the "leakage problem" of copyrighted materials onto the web are based on a lack of understanding about the possibilities of the Internet. If publishers were willing to work with libraries to create a standardized system of compliant green open access, academic libraries would be more efficient, which could decrease motivation to download illegal copies of papers.

\section{Publisher restrictions}

Publishers increasingly allow green open access, but without any consistency in policies or embargoes. This creates an unnecessary amount of work for institutions and authors to comply with the often-changing policies across disciplines and publishers. In many author agreements, authors assign copyright to the publisher and the publisher allows the right to post preprint (pre-peer review version) or postprint (after peer review version) copies on the web. Whatever justification publishers give for their arbitrary restrictions on green open access activities, they undermine their own justification with the diversity of policies, restrictions, embargoes, and versions they impose on depositing copies of published journal articles.

Publishers, who often claim they are supportive of green open access, work to impose restrictions on digital works as if they were physical items being placed in physical loca- tions. The looming fear of copyright violation for libraries and for authors influences the strict adherence to green open access stipulations, even though there is little legal underpinning for these restrictions. Legally, there is no precedent that versions of an article are protected under different copyrights. Although publishers will argue that copyediting and formatting are copyrightable, without added creativity or original expression, ${ }^{2}$ a final version is just another version of the same work, protected or restricted by the same copyright. Publishers may make clear in author contracts the uses and restrictions of postprint or preprint versions of a manuscript, but these are profit-motivated, not driven by copyright since there is no difference of copyright between versions. A policy that allows a postprint version, but not the final version, to be posted to a repository relies on the contract of the author agreement, not copyright.

Green open access policies are often buried on publisher's websites or only mentioned in contracts. This practice obfuscates important information, increasing both the time library staff spend searching for that information and author's obliviousness to the opportunities and restrictions of green open access. Searching for and complying with journal's unique green open access policies increases the effort required to post articles in repositories and decreases the perceived barriers to post on academic social media sites or personal pages as the restrictions are not obvious or visible.

Embargo lengths are not always clear, even in resources like Sherpa/Romeo, ${ }^{3}$ which are devoted to maintenance of this information. Further, even if an embargo is clearly stated, does the embargo period start at the time of online publication, assignment of volume and issue, print publication, or some other date? This lack of clarity opens to unnecessary risk for even diligent librarians attempting to comply.

Many journals require a "set statement" when a postprint copy is deposited in a repository. This practice is in line with 
academic norms: a full citation and link are provided with any other pertinent versioning information. However, as each publisher has a separate "set statement," the variety of these statements across publishers creates an inefficiency in compliance and speaks to a need to reform.

The mandated use of a postprint acts as a deterrent to the actualization of green open access, since multiple publishers do not ever provide an author with that version of a manuscript. Some only send a postprint to the corresponding author, and some merely send a final version for review. Many postprints arrive as HTML files and are not saved, or are hosted on publishing software and never actually in the hands of the researcher. Anecdotally, a researcher at my institution asked for a postprint of her recently published article from the journal editors and was emailed back a PDF of the publisher's version. Not even the journals had a copy (or understanding) of this version. This practice, whether purposefully or inadvertently, serves to protect the financial interests of publishers and delay the growth of repositories.

As funder and institutional open/public access mandates have increased, some publishers have changed their policies to allow a six-month embargo on personal sites, but a twelve- or eighteen-month embargo on institutional or subject repositories. ${ }^{4}$ This is in direct response to the existence of mandates that require an open access copy within 12 months of publication. In these cases, authors may be forced to pay for immediate open access to maintain compliance. This artificial restriction serves to complicate open access and increase income for a journal.

As a result of the difficult process of depositing postprints in repositories or a general lack of awareness about green open access, authors often upload the publisher's version of a paper to their own web page or to a commercial site like ResearchGate, with no regard for copyright or embargo, as "in reality authors seem to care little for such restrictions, in particular for copies uploaded to personal home pages or departmental pages." Since it is common practice for researchers to distribute copies of their papers through the mail, by fax, email, Twitter, etc., posting the publisher's version of a paper seems no different to them and removes the need for individual requests for copies of a paper. This common practice makes it harder to convince authors to go through the trouble to find a postprint of an article for the library-many of the benefits institutional repositories are proposing have already been fulfilled (though illegally) on their personal sites or by commercial platforms.

\section{Some possible solutions}

Time spent working toward copyright compliance is inefficient in the push for open access through institutional repositories. This inefficiency is especially apparent when it is compounded by illogical and changing restrictions that have little to do with copyright. If librarians are to keep working on this issue, we should work with publishers to increase the efficiency of our work so that we may advance the spread of knowledge while in compliance with reasonable restrictions.

If a publisher must impose restrictions on green open access copies of journal articles, they should ensure that those restrictions and stipulations are:

- Clear: Author's rights for reuse and reposting should be clear, correct, and machine readable.

- Consistent: Any restrictions or compliance instructions should be easily found and consistent across publishers, journals, and within fields. Publishers should have a set rule across their journals and make it clear if there is a variation (which should be avoided). Embargoes should be consistent as well, in length and across platforms.

- Reasonable: Journals should not ask for a postprint version to be posted if the only "postprint" they provide the author is in a web system and never a complete file.

- Fair: Journals should not punish (or

(continues on page 394) 
I began to think and brainstorm ideas on how to transition the content in a more inclusive way beyond the basic introductions done through webinars and conference presentations. Rather than present the ACRL Framework immediately, I needed to understand my colleagues' context and current teaching philosophies. My colleagues did not need a repeat of all the workshops and sessions they had attended or would attend. Rather, they needed help unpacking the document and more importantly, contextualizing the document and identifying where resources need to be allocated or are required.

\section{Conclusion}

I am guilty of frame-shaming. However, as I listen and reflect on my colleagues' reactions and experiences, I can empathize and hope that I can better facilitate a discussion to move towards more positive action. Brookfield writes that ". . . those of us who are trying to get colleagues to identify and question their assumptions, or to look at their practice through different lenses, must do the same." 6

Often the root of our reactions and actions are not always obvious. To better understand my colleagues, I needed to explore the assumptions I made with the workshop participants.

\section{Notes}

1. Jan Fook and Gurid Aga Askeland, "Challenges of Critical Reflection: 'Nothing Ventured, Nothing Gained,' Social Work Education, 26, no. 5 (2007): 528.

2. Stephen D. Brookfield, Becoming a Critically Reflective Teacher (San Francisco, Jossey-Bass, 1995), 8.

3. Ibid.

4. David Tripp, Critical Incidents in Teaching: Developing Professional Judgement (New York: Routledge, 1993).Tripp, Critical Incidents in Teaching, 59.

5. Tripp, Critical Incidents in Teaching, 59.

6. Brookfield, Becoming a Critically Reflective Teacher, 205.

("The enemy of the good. ..," continues from page 374)

attempt to persuade to pay open access charges) authors who are publishing with open access mandates from their funder or institution. There should not be differences between posting in an institutional repository and a personal webpage.

Current practices help perpetuate an artificial monopoly that inhibits knowledge dissemination and growth while giving the appearance of openness. The Internet has not merely increased access and availability of resources, it has opened an avenue to sharing that is inevitable. Like water through the cracks, information will find a path of least resistance, and it is in publisher's' best interest to promote a system that enables reasonable compliance for librarians and authors. As publishers struggle with illegal downloads and the potential security threat of platforms such as Sci-Hub, ${ }^{6}$ it behooves them to treat libraries and repositories as partners in the dissemination of knowledge rather than as adversaries. Ultimately, the more access researchers have to articles, the more those articles get cited, ${ }^{7}$ which increases impact factor and journal prestige. Since libraries need to maintain subscriptions for intuitional accreditation and performance, and increased citations benefit journals, ease of institutional repository deposit should be seen as an easy win for publishers.

\section{Notes}

1. World Intellectual Property Organization, "Berne Convention for the Protection of Literary and Artistic Works," www.wipo.int /treaties/en/ip/berne/.

2. Nancy Sims, "It's all the same to me! Copyright, contracts, and publisher self-archiving policies," College \& Research Libraries News 76 no. 11 (2016) 578-581.

3. Jisc, "Publisher copyright policies and self-archiving," www.sherpa.ac.uk

(continues on page 401) 
Pepperdine University has received a $\mathbf{\$ 1 . 3}$ million gift along with the Dr. Leonard B. and Joan R. Starr Art Book and Music Collection. The books and recordings from the collection will be preserved and displayed as part of the Starr Art Book and Music Collection, while the monetary gift will form an endowment that will be used to fund a curatorial position for, and periodic additions to, the collection. The collection is organized with a catalog created by Starr that identifies books containing specific works of art. Many of the books in the collection are limited edition publications, an additional benefit to researchers. Cataloging the collection is expected to take much of the rest of 2017.

\section{Northwestern University and Indiana Uni-}

versity have received a $\$ 967,000$ Institute of Museum and Library Services (IMLS) grant that will allow each university library to enhance their jointly developed audiovisual repository system, further improving the ability of archival institutions to manage and make accessible large digital collections of video and audio. The National Leadership Grant, LG-70-17-0042-17, from IMLS focuses on the functionality and sustainability of the open source tool, Avalon Media System. Avalon is designed to help institutions manage and deliver audio/video materials to faculty, students, and researchers.

\section{Acquisitions}

\section{Cornell University Library has acquired}

a collection documenting the U.S. textile industry. The collection, from the Osborne Library at the recently closed American Textile History Museum, comprises approximately

Ed. note: Send your grants and acquisitions to AnnChriste Galloway, production editor, C\&RL News, email: agalloway@ala.org.
90,000 books, periodicals, manuscript collections, photographs, textile sample books, tintypes, glass plate negatives, trade catalogs, and more, telling the story of the textile industry in New England and across the country. 2

("The enemy of the good...," continues from page 394)

/romeo/index.php.

4. An example of differing restrictions based on mandates or policies from the Sherpa Romeo database reads:

- Voluntary deposit by author of authors postprint allowed on institution's open scholarly website including Institutional Repository, without embargo, where there is not a policy or mandate.

- Deposit due to Funding Body, Institutional and Governmental policy or mandate only allowed where separate agreement between repository and the publisher exists.

- Permitted deposit due to Funding Body, Institutional and Governmental policy or mandate, may be required to comply with embargo periods of 12 months to 48 months, www.sherpa.ac.uk/romeo.

5. Björk, Bo-Christer, Mikael Laakso, Patrik Welling, and Patrik Paetau, "Anatomy of green open access," Journal of the Association for Information Science and Technology 65, no. 2 (2014): 237-50.

6. Bastian Greshake, "Looking into Pandora's Box: The Content of Sci-Hub and its Usage" [version 1; referees: 2 approved, 2 approved with reservations], F1000Research 6, no.541 (2017): http://dx.doi.org/10.12688 /f1000research.11366.1

7. Gunther Eysenbach, "Citation Advantage of Open Access Articles," PLoS Biology 4, no. 5 (2006): e157, https://doi.org/10.1371 /journal.pbio.0040157. 2 